\title{
A green approach to the analysis of co-administered ampicillin/sulbactam and paracetamol in human urine
}

\author{
BASMA M. SELIM ${ }^{1}$ \\ RANDA A. ABDELSALAM ${ }^{2}$ \\ ALAA EL-GINDY ${ }^{2}$ \\ BASMA G. EID ${ }^{3}$ \\ THIKRYAT NEAMATALLAH ${ }^{3}$ \\ AHDAB N. KHAYYAT ${ }^{4}$ \\ GHADA M. HADAD 2 \\ MAHMOUD M. ELKHOUDARY ${ }^{5, *}$ \\ ${ }^{1}$ Pharmaceutical Chemistry Department \\ Faculty of Pharmacy \\ Sinai University, North Sinai, Al'Arish, Egypt \\ ${ }^{2}$ Pharmaceutical Analytical Chemistry \\ Department, Faculty of Pharmacy \\ Suez Canal University, Ismailia, Egypt \\ ${ }^{3}$ Department of Pharmacology $\mathcal{E}$ Toxicology \\ Faculty of Pharmacy \\ King Abdulaziz University, Saudi Arabia \\ ${ }^{4}$ Department of Pharmaceutical Chemistry \\ Faculty of Pharmacy \\ King Abdulaziz University, Saudi Arabia \\ ${ }^{5}$ Pharmaceutical Chemistry Department \\ Faculty of Pharma \\ Horus University-Egypt, New Damietta, Egypt
}

\begin{abstract}
The novelty of this work is the simultaneous analysis of sulbactam (SUL), ampicillin (AMP), and paracetamol (PARA) in human urine samples, using the environmentally benign RP-HPLC method. A C18 column was used in chromatographic separation using potassium dihydrogen phosphate $\left(10 \mathrm{mmol} \mathrm{L}^{-1}\right.$, $\mathrm{pH}$ 5)/ethanol $(90 \%, V / V)$ as the mobile phase; flow rate was $1.00 \mathrm{~mL} \mathrm{~min}{ }^{-1}$. UV detection at $220 \mathrm{~nm}$ was used for quantification. The proposed method showed good linearity in the concentration ranges of 2.20-250.00 $\mu \mathrm{g} \mathrm{mL}^{-1}$ for SUL, 2.50-250.00 $\mathrm{gg} \mathrm{mL}^{-1}$ for PARA, and 14.50-250.00 $\mu \mathrm{g} \mathrm{mL}^{-1}$ for AMP. Direct injection of urine samples with no prior extraction was performed. This method was found successful in moving towards greener studies of drugs' urinary excretion, by decreasing hazardous solvent consumption and waste. Moreover, the method was applied to investigate the urinary excretion of the drugs and possible interaction between ampicillin and paracetamol.
\end{abstract}

Keywords: ampicillin, paracetamol, sulbactam, HPLC, green analytical chemistry, drug-drug interaction, urinary excretion

Accepted May 4, 2021

Published online May 5, 2021

Sulbactam (SUL, semi-synthetic beta-lactamase inhibitor), contains a beta-lactam ring that irreversibly binds to the beta-lactamase enzyme at or near its active site, hence blocking enzyme activity and preventing the degradation of other beta-lactam antibiotics (1). Ampicillin (AMP, semi-synthetic beta-lactam antibiotic) attaches to penicillin-binding proteins (PBPs), the enzymes responsible for the cell wall structure formation and hence arrests the synthesis of the cell wall (2). SUL/AMP is primarily excreted renally, thus its plasma concentration levels and half-life increase in renally impaired patients (3). Pharmacokinetics of SUL/AMP does not change in the pediatric population compared to adults (4). The main excretion mode of SUL/AMP is through the kidneys with a half-life of nearly $1 \mathrm{~h}$

\footnotetext{
*Correspondence; e-mail address: melkhodary@horus.edu.eg
} 
(3). The expected mean plasma concentration was $13-18 \mu \mathrm{g} \mathrm{mL} \mathrm{L}^{-1}$ with a volume of distribution of $17.2 \mathrm{~L}$ (3). Paracetamol (PARA) is a widely used over-the-counter analgesic and antipyretic drug (5). It is taken orally, absorbed from the gastrointestinal tract, then it is taken up by the blood to be distributed throughout the body and then metabolized in the liver (6). Although PARA is almost entirely excreted renally, its plasma concentration levels and half-life are similar in both healthy and renally-impaired subjects with increased risk of toxicity in patients with renal disease due to accumulation of sulphate and glucuronide conjugates in plasma (7). Studies showed that the pharmacokinetics of PARA was altered in the pediatric and geriatric population $(7,8)$. Nearly $1-4 \%$ is renally excreted intact in urine with a half-life of $2-4 \mathrm{~h}(8,9)$. The expected mean plasma concentration was $3-20 \mu \mathrm{g} \mathrm{mL}^{-1}$ with a volume of distribution of $0.9 \mathrm{~L} \mathrm{~kg}^{-1}(7)$.

SUL/AMP combination covers bacterial strains resistant to AMP, thus providing a broader coverage (10). PARA is generally given as an adjunct to antibiotics for symptomatic treatment as well as controlling high temperatures associated with these conditions (11).

Although several studies reported measuring AMP or SUL individually, only a few studies have analyzed both AMP and SUL. UHPLC-MS/MS and HPLC-UV methods have been employed for the quantification of AMP/SUL in bovine milk (12) and in pharmaceutical preparations (13). On the other hand, LC-MS and LC-MS/MS methods have been recently used for the analysis of plasma PARA as well as urine metabolites, either individually or with other concomitantly given drugs (14-16). These assays may, however, be time-consuming or complex requiring the inclusion of additives such as ion-pairing substances.

From an environmental perspective, there is currently an intention amongst analytical chemists towards the greening of RP-HPLC methods especially when we come to toxic solvents that are used heavily. Green analytical chemistry (GAC) was emerged in the 2000s (17) and is aimed to eliminate and reduce the use of hazardous substances in analytical methods to make them more environmentally friendly, more economic with retaining the effectiveness of the method (18). NEMI labeling is a well-accepted four-part pictogram tool used widely to determine the greenness of an analytical method (19). Eco-Scale is another tool that further considers environmental impact parameters in a quantitative manner in comparison to NEMI (20). In this analysis, a score is calculated from 100, whereby penalty points are subtracted, and a larger number (near to 100) indicates a greener analysis.

Drug-drug interaction is a term for adverse effects that occur when the efficacy or toxicity of one or more drugs is modified by another co-administered drug. PARA is metabolized by cytochrome P450 2E1 to $N$-acetyl- $p$-benzoquinone-imine (NAPQI) which is highly reactive and toxic $(8,21)$. A previous study of drug-drug interaction between PARA and $\beta$-lactam antibiotics revealed that an unknown adduct is formed between NAPQI (metabolite derived from PARA oxidation) and $\beta$-lactam antibiotics (e.g., AMP) and concluded that this reaction can decrease the effective concentration of $\beta$-lactam antibiotic when co-administered with PARA (22).

Therefore, the present study is aimed to develop a new, fast, and simple RP-HPLC-DAD method using environment-friendly solvents for the determination of SUL, PARA, and AMP in urine samples simultaneously. The developed method was then used to study the pattern of urinary excretion of these co-administered drugs and applied to investigate the previously hypothesized PARA and AMP drug-drug interaction. 


\section{EXPERIMENTAL}

\section{Chemicals and drugs}

Samples of SUL (99.80 \%), PARA (99.80 \%), and AMP (99.85\%) were obtained as gifts from Egyptian International Pharmaceutical Industries Company (EIPICO), Egypt. Absolute ethanol 99.9 \% (HPLC grade) was purchased from Merck, Germany. Analytical grade potassium dihydrogen phosphate and phosphoric acid were purchased from Sigma-Aldrich, USA.

UNASYN $^{\circledR}$ for parenteral injection labeled to contain $500 \mathrm{mg}$ SUL and $1000 \mathrm{mg}$ AMP was manufactured by Pfizer, Egypt. Novaldol ${ }^{\circledR}$ film-coated tablet is labeled to contain 1000 mg PARA and was manufactured by Sanofi, Egypt.

\section{Equipment}

A Hitachi LaChrom Elite HPLC coupled with an L-2455 diode array detector (DAD) was used. It is designed with a model series L-2000 organizer box, an L-2300 column oven, an L-2130 pump with a built-in degasser, and a Rheodyne 7725i injector with a 20- $\mu \mathrm{L}$ loop. A $150 \times 4.6 \mathrm{~mm}$ (i.d.), 5- $\mu \mathrm{m}$ octadecylsilane column (Inertsil C18, GL Sciences Inc., Japan) was used for separation and quantification. Scan mode (in the range of 200-350 nm with 1-nm interval) was used for UV detection and quantitative analysis was performed at $\lambda_{\max }$ of $220 \mathrm{~nm}$ for all the analyzed peaks.

\section{Chromatographic conditions}

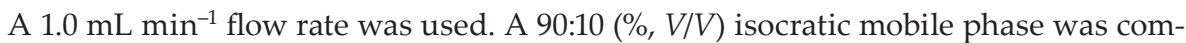
posed of $10 \mathrm{mmol} \mathrm{L}^{-1}$ potassium dihydrogen phosphate ( $\mathrm{pH}$ ) and absolute ethanol ( $99.9 \%$ ). The mobile phase was filtered through a $0.45-\mu \mathrm{m}$ Durapore ${ }^{\circledR}$ membrane filter (Merck Life Science, Pvt. Ltd., India), then degassed prior to use. Standards and human urine samples were injected in volumes of $20 \mu \mathrm{L}$. The column temperature was set at $25^{\circ} \mathrm{C}$.

\section{Standard solutions}

A $100 \mathrm{~mL}$ of stock solutions of each SUL (50 mg), AMP (100 mg), and PARA (50 mg) were prepared. SUL and AMP were dissolved in water and stored in a refrigerator whereas PARA was dissolved in ethanol and stored at $-20^{\circ} \mathrm{C}$ until analysis. Aliquots of SUL, AMP, and PARA stock solution were spiked with drug-free human urine in a volumetric flask and diluted to the required volume using the mobile phase to help to develop and optimizing the HPLC method. Then the working solutions for calibration runs were prepared by further dilution with the mobile phase $\left(2.2-250.0 \mu \mathrm{g} \mathrm{mL} \mathrm{m}^{-1}\right.$ for SUL, $2.5-250.0 \mu \mathrm{g} \mathrm{mL}^{-1}$ for PARA, and 14.5-250.0 $\mu \mathrm{g} \mathrm{mL}^{-1}$ for AMP). Twenty- $\mu \mathrm{L}$ injections were applied three times for each under the specified chromatographic conditions.

\section{Urine samples}

Drug-free urine was obtained from six (three males and three females with age range $31.0 \pm 12.0$ years and average weight of $78.0 \pm 14.0 \mathrm{~kg}$ ) healthy (normal electrocardiogram, 
liver, and kidney function tests) volunteers. Volunteers were informed to abstain from all other medications for 2 weeks before and during the study. The study protocol conforms to the Egyptian community guidelines for the in vivo studies and was approved by the Human Ethics Committee (No. 201901R1) of Faculty of Pharmacy, Suez Canal University, Cairo, Egypt.

The concentration of the collected urine samples was adjusted to fit the calibration range of SUL, PARA, and AMP by dilution with the mobile phase. Each 10-fold diluted urine sample was injected three times.

\section{Method validation}

The developed method was validated in accordance with ICH Q2 R1 guidelines (23). The parameters assessed were linearity, range, precision, detection and quantitation limits, selectivity, accuracy, and robustness.

Chromatographic parameters/system suitability. - Test parameters for the system suitability were checked to ensure that the proposed chromatographic system is working properly during the analysis process. All system suitability parameters were calculated using the built-in software equations (Table I).

Specificity. - Specificity of the proposed method was investigated by comparing blank urine, analytes enriched urine sample, and patents urine sample chromatograms (Fig. 1). For this purpose, $20 \mu \mathrm{L}$ of six different samples were injected into the HPLC system separately. The interference from sample endogenous compounds was investigated by recording retention times and peak purity values.

Linearity and range. - The linearity of SUL, PARA, and AMP was investigated by studying a series of different concentrations of each compound in the absence or presence of drug-free human urine samples (Table II). Six concentrations were selected, ranging between 2.2-250.0 $\mu \mathrm{g} \mathrm{mL}^{-1}$ for SUL, 2.5-250.0 $\mu \mathrm{g} \mathrm{mL} \mathrm{m}^{-1}$ for PARA, and $14.5-250.0 \mu \mathrm{g} \mathrm{mL}^{-1}$ for AMP. Each concentration was injected in triplicate.

Precision. - Precision was computed by analyzing three varying concentrations in the linearity range for SUL, PARA, and AMP spiked into drug-free human urine samples.

Table I. Chromatographic parameters for determination of sulbactam, ampicillin, and paracetamol

\begin{tabular}{cccccccc}
\hline Analyte & $\begin{array}{c}\text { Retention } \\
\text { time } \\
(\mathrm{min})^{\mathrm{a}}\end{array}$ & $\begin{array}{c}\text { Capacity } \\
\text { factor } \\
\left(k^{\prime}\right)\end{array}$ & $\begin{array}{c}\text { Selectivity } \\
(\alpha)\end{array}$ & $\begin{array}{c}\text { Resolution } \\
\left(R_{\mathrm{s}}\right)\end{array}$ & $\begin{array}{c}\text { Tailing } \\
\text { factor }\end{array}$ & $\begin{array}{c}\text { Retention } \\
\text { time } \\
\text { precision } \\
(\mathrm{RSD}, \%)\end{array}$ & $\begin{array}{c}\text { Plate } \\
\text { count } \\
(N)\end{array}$ \\
\hline SUL & $3.22 \pm 0.02$ & 2.22 & $1.64\left(\mathrm{a}_{1}\right)$ & $2.82\left(\mathrm{~b}_{1}\right)$ & 1.41 & 0.6 & 4495 \\
PARA & $4.63 \pm 0.04$ & 3.63 & $1.79\left(\mathrm{a}_{2}\right)$ & $3.61\left(\mathrm{~b}_{2}\right)$ & 1.19 & 0.9 & 7361 \\
AMP & $7.51 \pm 0.05$ & 6.51 & & & 1.00 & 0.7 & 6444 \\
\hline
\end{tabular}

The retention time of the unretained mobile phase peak is $1 \mathrm{~min}$. $\mathrm{a}_{1}, \mathrm{~b}_{1}-\alpha$ and $R_{\mathrm{s}}$ calculated for SUL/PARA; $\mathrm{a}_{2}, \mathrm{~b}_{2}-\alpha$ and $R_{\mathrm{s}}$ calculated for PARA/AMP

${ }^{\mathrm{a}}$ Mean $\pm \mathrm{SD}, n=7$. 
B. M. Selim et al.: A green approach to the analysis of co-administered ampicillin/sulbactam and paracetamol in human urine, Acta Pharm. 72 (2022) 259-274.

a)

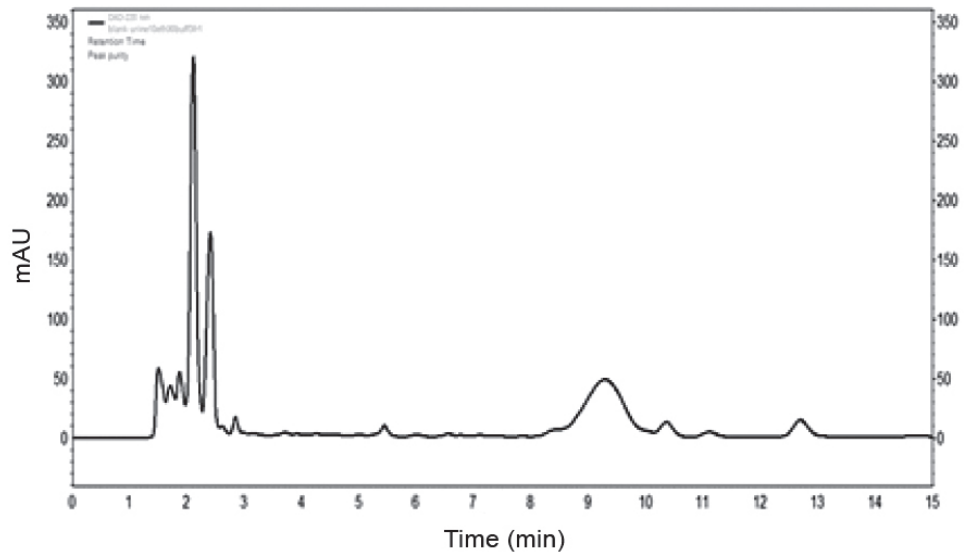

b)

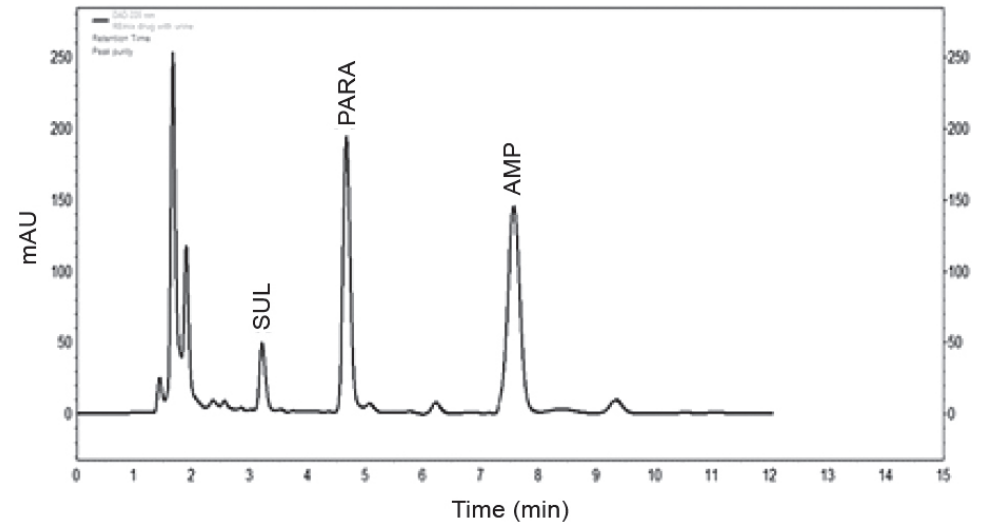

c)

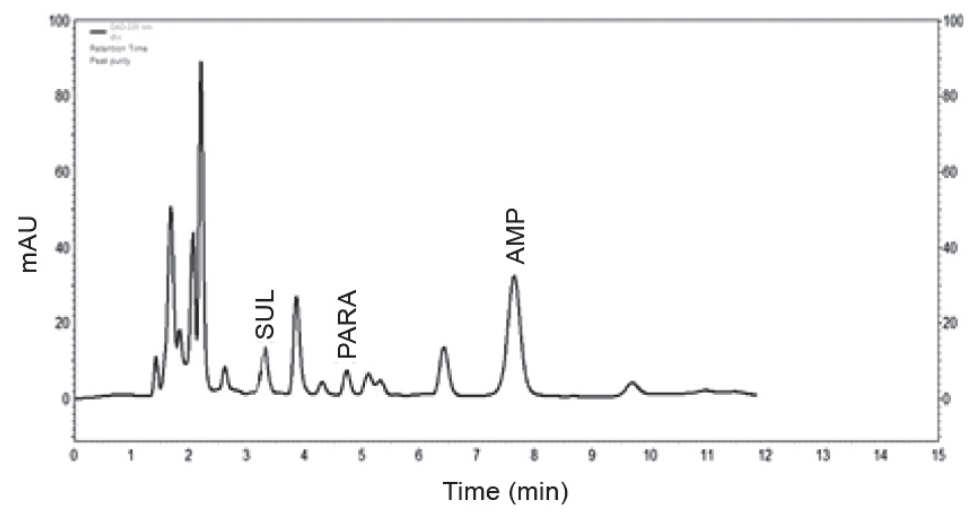

Fig. 1. Typical HPLC chromatogram of: a) blank human urine (volunteer 4), b) $50 \mu g \mathrm{~mL}^{-1} \mathrm{SUL}, 50 \mu \mathrm{g} \mathrm{mL}$ PARA and $100 \mu \mathrm{g} \mathrm{mL}^{-1}$ AMP standards spiked to blank human urine (volunteer 2), c) human urine (volunteer 1) $4 \mathrm{~h}$ after a single administration of UNASYN ${ }^{\circledR}$ injection (500 mg SUL and $1000 \mathrm{mg}$ AMP) and Novaldol ${ }^{\circledR}$ tablet (1000 mg PARA). 
B. M. Selim et al.: A green approach to the analysis of co-administered ampicillin/sulbactam and paracetamol in human urine, Acta Pharm. 72 (2022) 259-274.

Table II. Regression analysis for HPLC method for determination of sulbactam, ampicillin, and paracetamol in the human urine

\begin{tabular}{lccc}
\hline Parameter & SUL & PARA & AMP \\
\hline Calibration range $\left(\mu \mathrm{g} \mathrm{mL}^{-1}\right)$ & $2.20-250.00$ & $2.50-250.00$ & $14.50-250.00$ \\
Detection limit $\left(\mu \mathrm{g} \mathrm{mL}^{-1}\right)$ & 0.66 & 0.82 & 4.47 \\
Quantitation limit $\left(\mu \mathrm{g} \mathrm{mL}^{-1}\right)$ & 1.99 & 2.49 & 13.56 \\
Regression equation ${ }^{\mathrm{a}}$ : & & & $9.01 \times 10^{4}$ \\
Slope $(b)$ & $2.72 \times 10^{4}$ & $1.48 \times 10^{5}$ & $1.57 \times 10^{3}$ \\
Standard deviation of the slope $\left(S_{\mathrm{b}}\right)$ & $1.39 \times 10^{2}$ & $9.42 \times 10^{2}$ & $-1.39 \times 10^{5}$ \\
Confidence limits of the slope ${ }^{\mathrm{b}}$ & $2.68 \times 10^{4}-2.76 \times 10^{4}$ & $1.45 \times 10^{5}-1.50 \times 10^{5}$ & $8.58 \times 10^{4}-9.45 \times 10^{4}$ \\
Intercept $(a)$ & $2.04 \times 10^{5}$ & $1.07 \times 10^{5}$ & $9.51 \times 10^{4}$ \\
Standard deviation of the intercept $\left(S_{\mathrm{a}}\right)$ & $4.21 \times 10^{3}$ & $2.86 \times 10^{4}$ & 0.9988 \\
Confidence limits of the intercept ${ }^{\mathrm{b}}$ & $1.92 \times 10^{5}-2.15 \times 10^{5}$ & $2.77 \times 10^{4}-1.86 \times 10^{5}$ & $-4.03 \times 10^{5}-1.25 \times 10^{5}$ \\
Correlation coefficient $(R)$ & 0.9999 & 0.9998 & $1.22 \times 10^{3}$ \\
Standard error of the estimate $(\mathrm{SEE})$ & $5.41 \times 10^{3}$ & $3.67 \times 10^{4}$ & \\
\hline
\end{tabular}

${ }^{\mathrm{a}} y=a+b \gamma$, where $y$ is the peak area, $a$ is the intercept, $b$ is the slope, and $\gamma$ is the concentration of SUL, PARA, and $\mathrm{AMP}\left(\mu \mathrm{g} \mathrm{mL}^{-1}\right)$ in human urine. ${ }^{\mathrm{b}} 95 \%$ confidence limits.

Assessment of intra-day precision was determined from the results of 5 replicate analyses on the same day of each sample (Table III). Determination of inter-day precision was carried out by analyzing samples consecutively on five days. RSD was calculated to evaluate the precision of the results.

Limit of detection and quantitation. - Limit of detection $(L O D)$ and limit of quantitation $(L O Q)$ for SUL, PARA, and AMP were determined by the standard deviation of the response and the slope method (23). They were calculated as $3.3 \alpha / S$ and $10 \alpha / S$, resp., where $\alpha$ is the standard deviation of the $y$-intercept and $S$ is the slope of the regression line (Table II).

Accuracy. - Accuracy was assessed using the standard addition method. Different concentrations of SUL, PARA, and AMP (within the linearity range concentration) were spiked into blank human urine samples and pre-analyzed, then various amounts of each drug were added to the spiked samples and were subsequently analyzed in order to test for accuracy (Table IV).

Robustness. - Influence of minor deliberate changes in the conditions like flow rate, buffer concentration in addition to $\mathrm{pH}$ and strength of the mobile phase of the proposed HPLC method on critical system suitability parameters was tested (Table V).

Stability. - The studied compounds' solutions were tested for changes at both room and refrigerator $\left(4.0^{\circ} \mathrm{C}\right)$ temperatures either exposed or protected from light. 

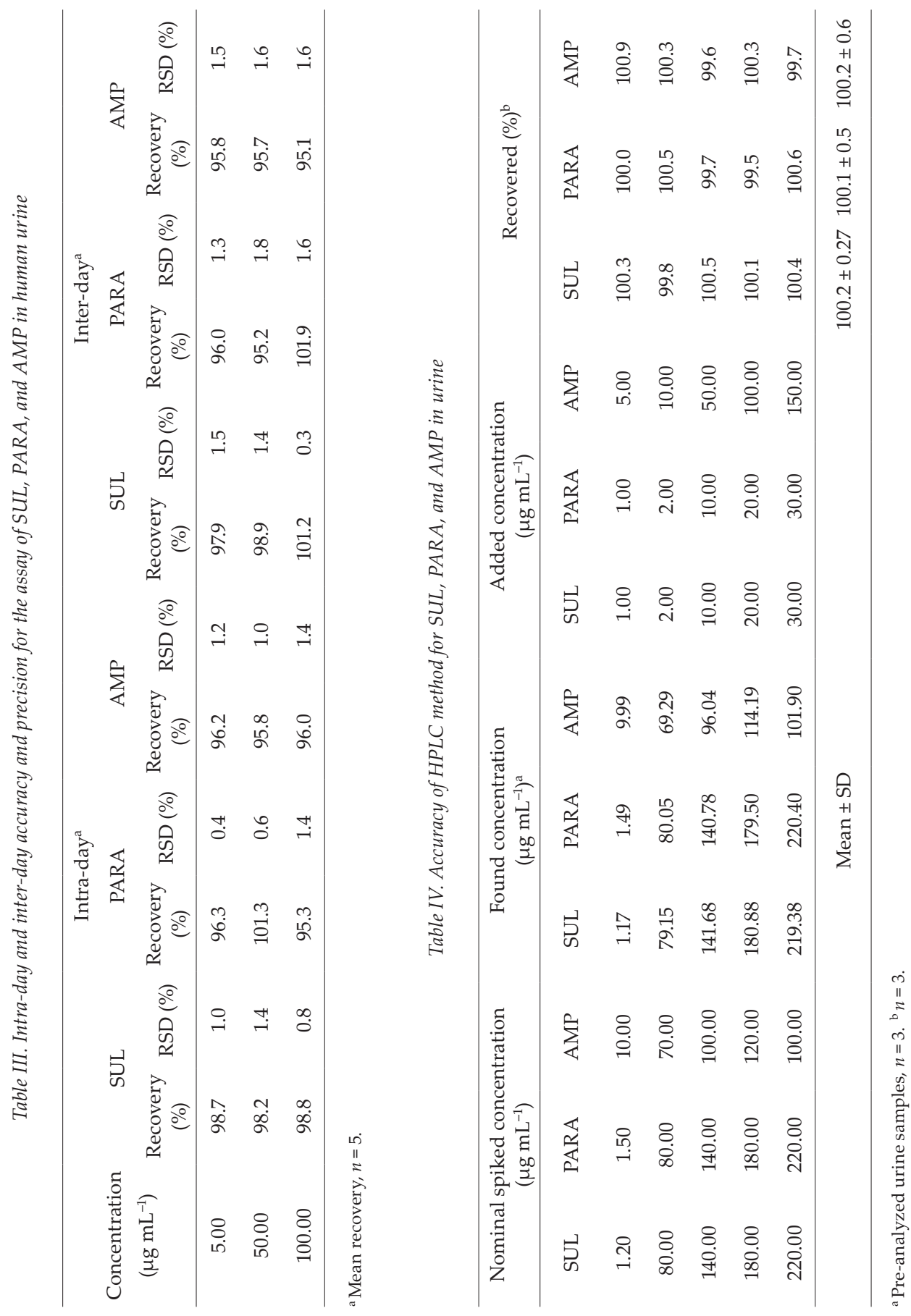


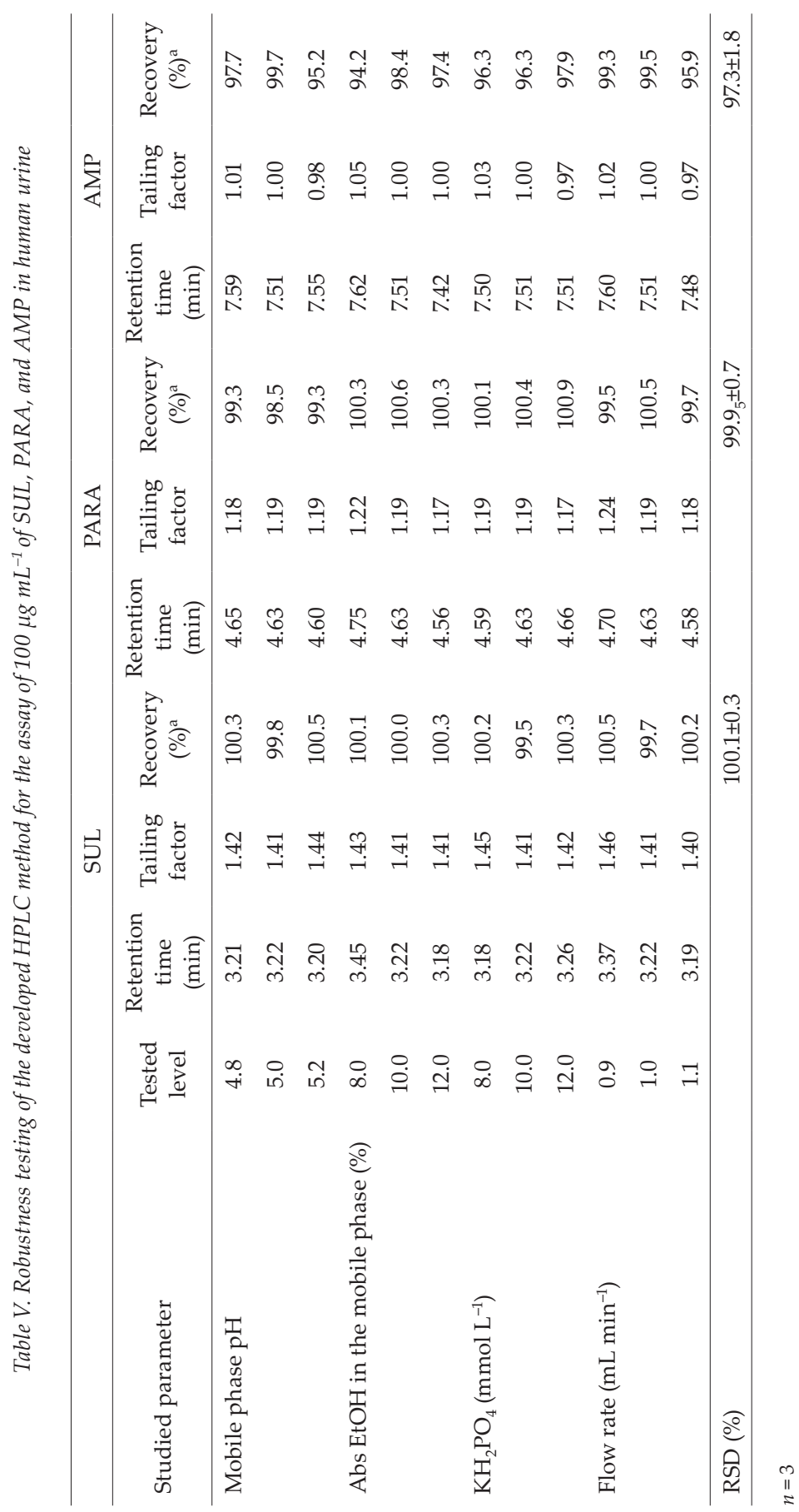




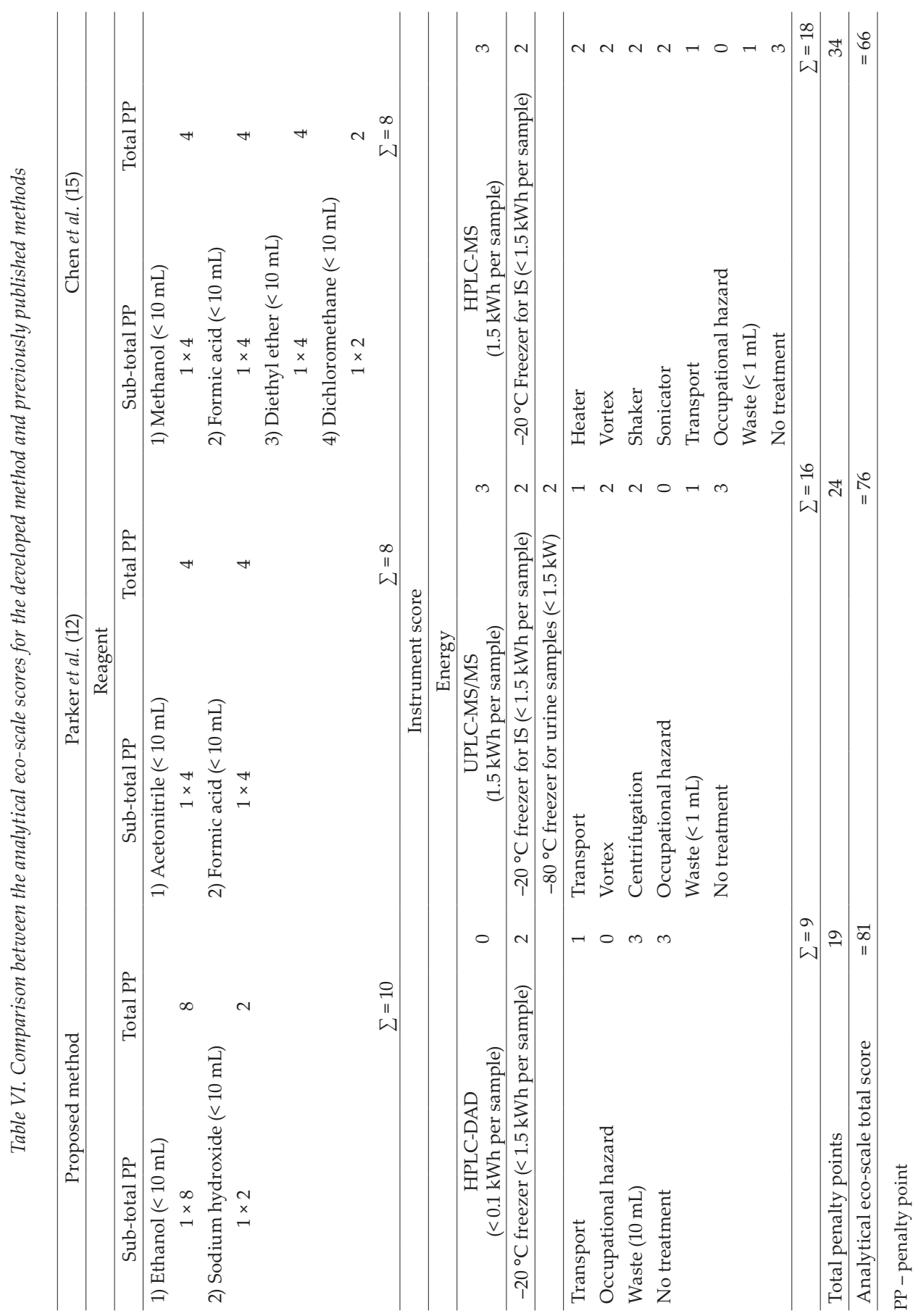


The greenness of the proposed method using analytical eco-scale

The analytical eco-scale assigns penalty points to some parameters related to the analysis method; the penalty points focus on the amount and hazards of reagents as well as instrument energy efficiency and produced waste. The methodology of calculation of penalty points is explained in detail in the previously published article (20). Three classes can be assigned to the developed analytical method after subtracting penalty points from 100: excellent, acceptable, and inadequate if the Eco-Scale value is more than 75, more than 50, and less than 50, resp.

\section{Application to urinary excretion study of AMP, SUL, and PARA}

To check the clinical applicability of the method, the urinary excretion pattern of SUL, PARA, and AMP were investigated using the proposed method. Six volunteers partici-

a)

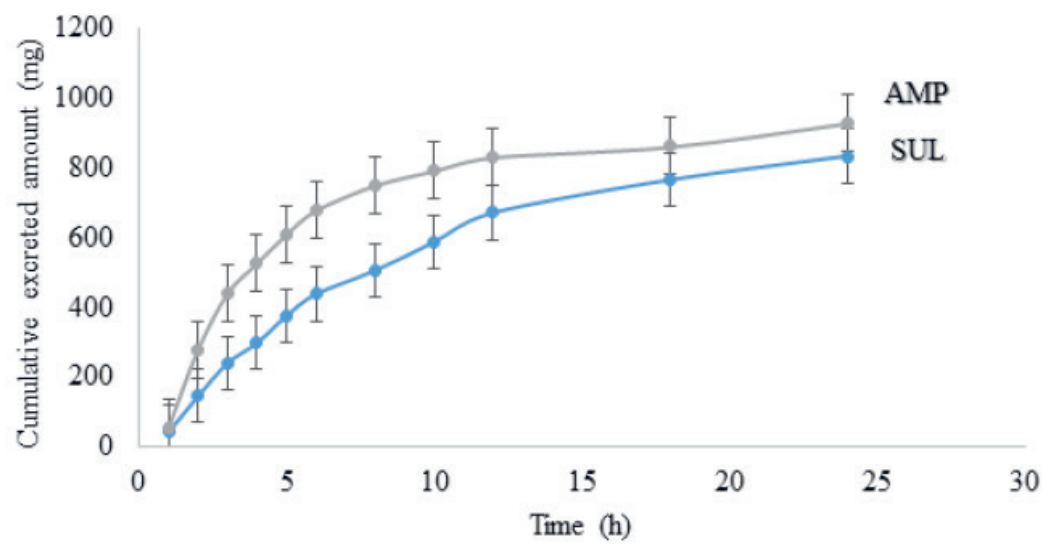

b)

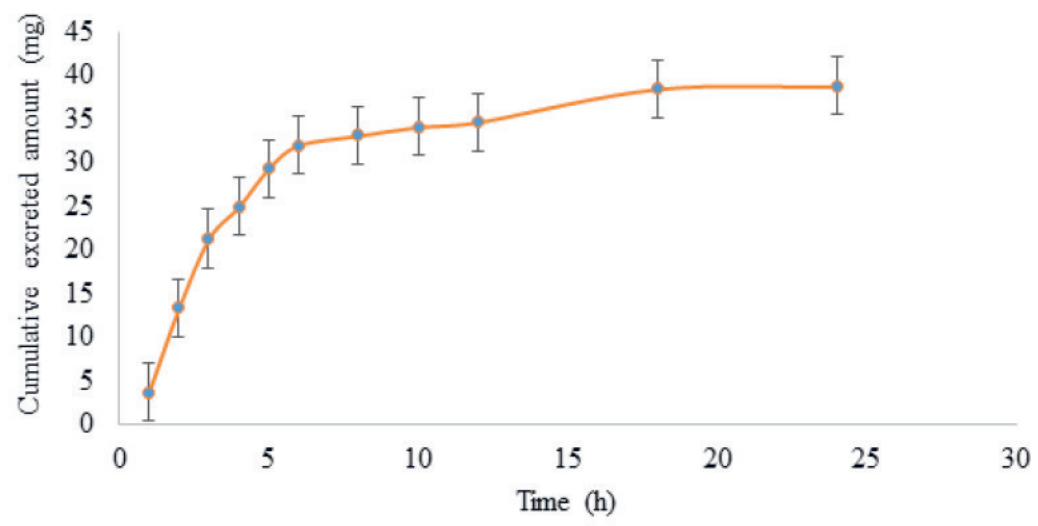

Fig. 2. Cumulative excretion of: a) SUL and AMP and b) PARA in the urine of a healthy human volunteer after a single administration UNASYN ${ }^{\circledR}$ injection (500 mg SUL and $1000 \mathrm{mg}$ AMP) and of Novaldol ${ }^{\circledR}$ tablet (1000 mg PARA). Mean \pm SD, $n=6$. 
a)

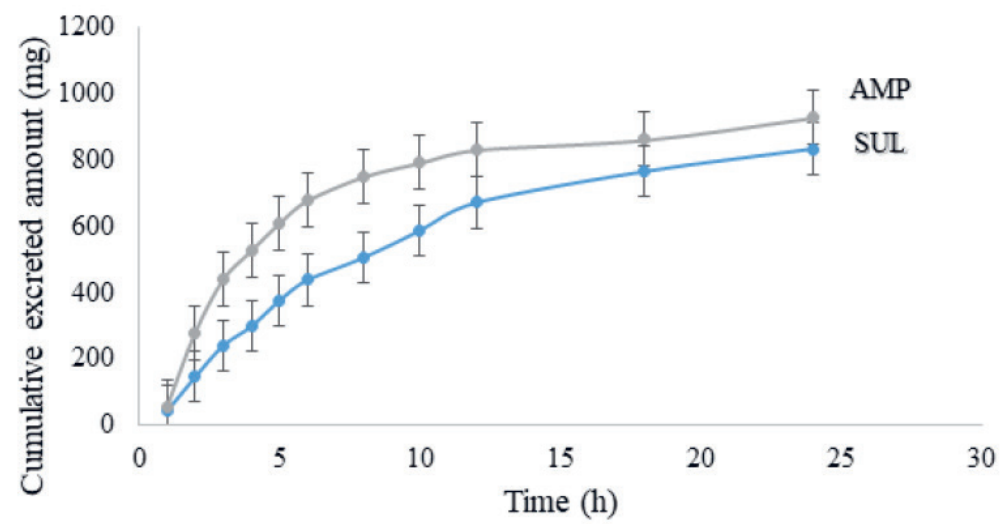

b)

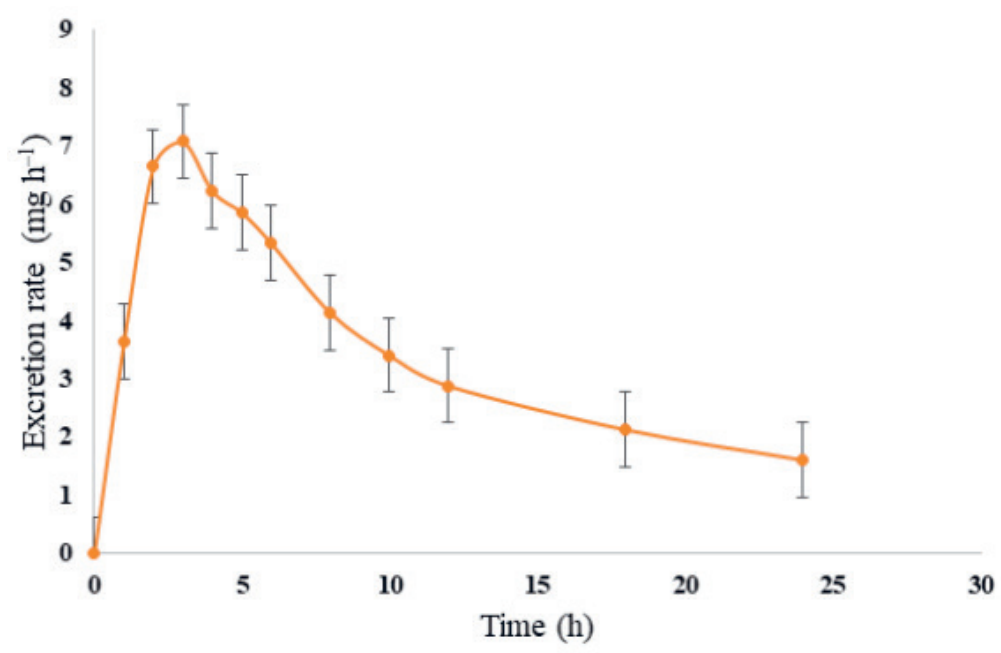

Fig. 3. Mean urinary excretion rate-time profiles of: a) SUL and AMP and b) PARA in urine donors after a single administration of UNASYN ${ }^{\circledR}$ injection (500 mg SUL and $1000 \mathrm{mg}$ AMP) and Novaldol ${ }^{\circledast}$ tablet (1000 mg PARA). Mean \pm SD, $n=6$.

pated in a cross-over randomized study. A parenteral administration of $500 \mathrm{mg}$ SUL and $1000 \mathrm{mg}$ AMP (UNASYN ${ }^{\circledR}, 1500 \mathrm{mg}$ per vial), as well as $1000 \mathrm{mg}$ PARA orally (single dose Novaldol ${ }^{\circledR}, 1000 \mathrm{mg}$ per tablet), were given to six volunteers fed a standardized low-fat meal (400-500 kcal out of which $150 \mathrm{kcal}$ for fats to avoid induced food-drug interactions), 30 minutes before drug administration and after overnight 10-hour fasting. Also, they were guided to evacuating their bladder as thoroughly as possible just before the administration of drug doses. Subsequently, volunteers were not allowed to have meals for 4 hours except for water. The urine samples that were taken pre-dose were considered as a blank then the following post-dose samples were taken in the specified time intervals of $0-1,1-2,2-3,3-4,4-5,5-8,8-12,12-18,16-24 \mathrm{~h}$. The urine volume was recorded every time and stored at $-20^{\circ} \mathrm{C}$ prior to analysis. 
The control study was carried out by two of the six volunteers. They were selected randomly using computer-generated random numbers and administered one of the two studied medications (UNASYN ${ }^{\circledR}$ injection or Novaldol ${ }^{\circledR}$ tablet) to help investigate the interaction between AMP and PARA. This was done after a washing period (drug-free period) of one month to ensure complete removal of the effect of other drugs and to avoid overlap between drugs' action.

The urine concentrations were directly calculated for all time intervals from the collected chromatographic data. Urinary excretion study of each drug was done for the following parameters: excretion amount, excretion rate, cumulative excretion amount, and cumulative excretion percentage.

\section{RESULTS AND DISCUSSION}

\section{Optimization of chromatographic conditions}

Ethanol was selected as an organic modifier due to its green characteristics, availability, and relatively low cost. The influence of $\mathrm{pH}$ of the mobile phase and ethanol concentration on the capacity factor $\left(k^{\prime}\right)$ of each compound were investigated to optimize HPLC parameters. Lowering the ethanol concentration to less than $5 \%$ resulted in increased retention time of AMP peak (the most retained peak) causing significant band broadening and extreme tailing, whereas an ethanol concentration over $30 \%$ decreased retention time resulting in insufficient separation between the separated drugs and endogenous components of urine. A mobile phase with $10 \%$ ethanol achieved the best chromatographic characteristics for the separated peaks with reasonable retention times.

The role of $\mathrm{pH}$ of the mobile phase was investigated using potassium dihydrogen phosphate buffer with a $\mathrm{pH}$ range of 3.0-6.0. At $\mathrm{pH}$ 6.0, the symmetry of the AMP peak deteriorated with a considerable increase in its capacity factor. On the other hand, the mobile phase with $\mathrm{pH} 3.0$ resulted in deteriorated SUL peak resolution with severe overlap with endogenous urine components. Resolution of the three peaks was better at $\mathrm{pH} 4.0-$ 5.0; however, at $\mathrm{pH} 5.0$ optimum resolution with reasonable retention time was noted for both SUL and AMP peaks. Influence of potassium dihydrogen phosphate concentration in buffer solution was tested between 10.0 and $50.0 \mathrm{mmol} \mathrm{L}^{-1}$ and it had minimal effect on both peak shape and retention behavior of SUL, PARA, and AMP. The concentration of 10.0 mmol L-1 was the lowest $\mathrm{KH}_{2} \mathrm{PO}_{4}$ concentration which caused the least damage to the column and enhanced the greenness of the method.

Eventually, the mobile phase consisted of $\mathrm{KH}_{2} \mathrm{PO}_{4}$ solution $(10.0 \mathrm{mmol} \mathrm{L}-1, \mathrm{pH} 5.0)$ : abs. ethanol (90:10) was found suitable for the separation of SUL, PARA, and AMP from endogenous components of urine. A flow rate of $1.0 \mathrm{~mL} \mathrm{~min}^{-1}$ at ambient temperature was used with UV detection at $220 \mathrm{~nm}$ for quantification.

No interfering peaks were seen at the retention times of SUL, PARA, and AMP in the chromatograms of blank human urine (Fig. 1). Fig. 2 shows typical chromatograms for human urine samples spiked with SUL, PARA, and AMP and it shows that the drugs were well separated from endogenous urine peaks. The average retention times for SUL, PARA, and AMP were found to be 3.22, 4.63, and $7.51 \mathrm{~min}$, resp. Sharp peaks with obvious baseline separations were obtained. Table I gives the chromatographic parameters. 


\section{Validation of the method}

After optimizing the chromatographic conditions and due to the limited matrix interference and lack of extraction procedures, the ICH Q2 R1 guidelines were found suitable and followed to validate the optimized method and prove it to fit its purpose (23).

Specificity. - No interfering peaks from co-eluting matrix compounds were observed at the retention times of SUL, PARA, and AMP spiked in diluted blank urine samples from six different donors (Fig. 3). The peak purity values of the three drugs' peaks were more than 0.99 which confirms the lack of interference from co-eluting matrix compounds.

Linearity and range. - The assay was performed according to previously established experimental conditions. Six concentrations were selected, ranging between 2.2-250.0 $\mu \mathrm{g} \mathrm{mL}{ }^{-1}$ for SUL, 2.5-250.0 $\mu \mathrm{g} \mathrm{mL}^{-1}$ for PARA and $14.5-250.0 \mu \mathrm{g} \mathrm{mL}{ }^{-1}$ for AMP. Regression data obtained by the least-squares treatment are given in Table II (correlation coefficient $>0.99$ ). The calibration graphs for each drug either in the presence or absence of drug-free human urine manifested good linearity, so the one determined in the presence of drug-free human urine samples (matrix-matched calibration) was adopted for method validation and quantitation in real samples.

Precision. - RSD was lower than $2 \%$ (namely, 0.3-1.6 \%), for both intra- and inter-day assays in human urine samples confirming good precision. This additionally proves the controllable interference from the endogenous urine components (Table III).

Limits of detection and quantitation. - Table II also lists the estimated values of $L O D$ and LOQ. $L O D$ values of $0.66,0.82$, and $4.47 \mu \mathrm{g} \mathrm{mL}^{-1}$ for SUL, PARA, and AMP, resp., while LOQs were three times as high as LODs (Table II).

Accuracy. - The resulting standard addition mixtures were assayed, and results calculated for SUL, PARA, and AMP were compared with expected results. Recoveries of 99.5$100.9 \%$-suggested acceptable accuracy of the proposed method in human urine (Table IV).

Robustness. - Variation of $\mathrm{pH}$ of the mobile phase by \pm 0.2 units, $\mathrm{KH}_{2} \mathrm{PO}_{4}$ concentration by $\pm 2 \mathrm{mmol} \mathrm{L}^{-1}$, the abs. ethanol concentration in the mobile phase by $\pm 2 \%$ and the flow rate by $0.2 \mathrm{~mL} \mathrm{~min}^{-1}$ did not affect drugs retention and tailing, neither analytes recovery, considerably (Table V).

Stability. - It was determined that SUL, PARA, and AMP were stable in the mobile phase at room temperature, for a minimum of 4 hours. Urine samples spiked with SUL, PARA, and AMP following three freeze/thaw cycles at $-20^{\circ} \mathrm{C}$ for one week and at $3{ }^{\circ} \mathrm{C}$ for one day, were also stable.

\section{The greenness of the proposed method using analytical eco-scale}

Calculated penalty points for different parameters of the developed HPLC-DAD method are demonstrated in Table VI. The score (81 out of 100) of the developed method proves that it is an excellent method of analysis in terms of greenness. The comparison of the developed method with the simplest previously published ones analyzing either SUL/ AMP (12) or PARA (15) in biological matrices revealed that our method performs better in 
terms of greenness where minimal consumption of toxic reagents was required and more energy-efficient HPLC/UV instrument was used compared with reported LC/MS ones. Moreover, no sample pretreatment steps (e.g., vortex mixing, shaking, centrifugation) were adopted in the newly developed method that was able to simultaneously determine SUL, AMP and PARA.

\section{Application to urinary excretion study of AMP, SUL, and PARA}

The proposed method was assessed for its performance by applying it to urine samples from volunteers taking UNASYN ${ }^{\circledR}$ and Novaldol ${ }^{\circledR}$ medication. HPLC chromatogram of a real human urine sample 4 hours after receiving the drugs is shown in Fig. 1. Concentrations of SUL, PARA, and AMP in diluted urine samples were found to be 22.7, 10.1, and $25.8 \mu \mathrm{g} \mathrm{mL} \mathrm{m}^{-1}$, resp., after $4 \mathrm{~h}$.

The mean values of urinary excretion rate-time profiles and cumulative excretion amount-time profiles of SUL, PARA, and AMP in six volunteers are shown in Figs. 2 and 3. From these profiles, we can conclude that excretion rates of SUL, PARA, and AMP reached a maximum after $3 \mathrm{~h}$. For SUL, the 8-h cumulative excretion amount in human urine was $505.56 \pm 14.52 \mathrm{mg}$, which represented $101.9 \pm 3.5 \%$ of the total dose. For AMP, the 24-h cumulative excretion amount in human urine was $928.7 \pm 18.5 \mathrm{mg}$, which represented $92.9 \pm 4.6 \%$ of the total dose. For PARA, the 24 -h cumulative excretion amount in human urine was $38.78 \pm 4.51 \mathrm{mg}$, which represented $3.88 \pm 0.50 \%$ of the total dose.

These results indicate that SUL is excreted unchanged in the urine in total after only $8 \mathrm{~h}$ as previously mentioned, whereas AMP excretion was affected by the interaction with PARA that led to the delay of AMP excretion. It took $8 \mathrm{~h}$ for only $50.6 \%$ of AMP to be excreted, whereas the same amount took only one hour to be excreted when the volunteer in the control group was administered UNASYN ${ }^{\circledR}$ injection alone (SUL+AMP). This observation was consistent with the previously described half-life of the drug of 1 hour (3). PARA urinary excretion behavior did not alter (in either volunteer in drug intervention or control group) from the previously mentioned range, where less than $4.0 \%$ of the drug was excreted unchanged in the urine. The results support that there is some sort of drug-drug interaction that was evident in the alteration of the elimination behavior of AMP. This may be explained by the formation of an adduct from PARA oxidative metabolite (NAPQI) and the $\beta$-lactam antibiotic (AMP) (21).

\section{CONCLUSIONS}

A green RP-HPLC method for the determination of SUL, PARA, and AMP in human urine has been developed and preliminarily validated. It is relatively simple and rapid to perform a urinary excretion study, without any sample preparation prior to chromatography. High selectivity, precision, accuracy, and robustness enable its applicability to the routine quantitation of SUL, PARA, and AMP excreted in human urine. A clear advantage of this method is that it has adopted a green approach with widely available simple HPLC instrumentation rather than sophisticated alternatives, e.g., LC-MS/MS.

The urinary excretion pattern of the SUL, PARA, and AMP was demonstrated; a delay in the excretion of AMP upon co-administration with PARA was evidenced, suggesting the need for caution when the two drugs are co-administered. 


\section{REFERENCES}

1. J. Noguchi and M. Gill, Sulbactam: a beta-lactamase inhibitor, Clin. Pharm. 7 (1988) 37-51.

2. T. K. Jellison, P. S. McKinnon and M. J. Rybak, Epidemiology, resistance, and outcomes of Acinetobacter baumannii bacteremia treated with imipenem-cilastatin or ampicillin-sulbactam, Pharmacotherapy 21 (2001) 142-148; https://doi.org/10.1592/phco.21.2.142.34114

3. D. M. Campoli-Richards and R. N. Brogden, Sulbactam/ampicillin, Drugs 33 (1987) 577-609; https://doi.org/10.2165/00003495-198733060-00003

4. M. C. Nahata, V. I. Vashi, R. N. Swanson, M. A. Messig and M. Chung, Pharmacokinetics of ampicillin and sulbactam in pediatric patients, Antimicrob. Agents Chemother. 43 (1999) 1225-1229; https://doi.org/10.1128/AAC.43.5.1225

5. A. Walsh, H. Edwards and J. Fraser, Over-the-counter medication use for childhood fever: a crosssectional study of Australian parents, J. Paediatr. Child Health 43 (2007) 601-606; https://doi. org/10.1111/j.1440-1754.2007.01161.x

6. S. Koling, G. Hempel, C. Lanvers, J. Boos and G. Würthwein, Monitoring paracetamol metabolism after single and repeated administration in pediatric patients with neoplastic diseases, Int. J. Clin. Pharm. Ther. 45 (2007) 496-503; https://doi.org/10.5414/cpp45496

7. J. A. Forrest, J. Clements and L. Prescott, Clinical pharmacokinetics of paracetamol, Clin. Pharmacokinet. 7 (1982) 93-107.

8. A. Bertolini, A. Ferrari, A. Ottani, S. Guerzoni, R. Tacchi and S. Leone, Paracetamol: new vistas of an old drug, CNS Drug Rev. 12 (2006) 250-275; https://doi.org/10.1111/j.1527-3458.2006.00250.x

9. C. Oscier and Q. Milner, Peri-operative use of paracetamol, Anaesthesia 64 (2009) 65-72; https://doi. org/10.1111/j.1365-2044.2008.05674.x

10. C. Gonzalez, A. Garcia, R. Urrea, H. Bello and R. Zemelman, A combination of ampicillin and sulbactam: effect on aerobic and anaerobic gram-negative bacteria, Rev. Méd. Chile 118 (1990) 548-554.

11. S. T. Shulman, A. L. Bisno, H. W. Clegg, M. A. Gerber, E. L. Kaplan, G. Lee, J. M. Martin and C. Van Beneden, Clinical practice guideline for the diagnosis and management of group A streptococcal pharyngitis: 2012 update by the Infectious Diseases Society of America, Clin. Infect. Dis. 55 (2012) e86-e102; https://doi.org/10.1093/cid/cis629

12. S. L. Parker, S. Adnan, J. L. Ordóñez Meija, D. L. Paterson, J. Lipman, J. A. Roberts and S. C. Wallis, An UHPLC-MS/MS method for the simultaneous determination of ampicillin and sulbactam in human plasma and urine, Bioanalysis 7 (2015) 2311-2319; https://doi.org/10.4155/bio.15.143

13. T. L. Tsou, Y. C. Huang, C. W. Lee, A. R. Lee, H. J. Wang and S. H. Chen, Simultaneous determination of ampicillin, cefoperazone, and sulbactam in pharmaceutical formulations by HPLC with $\beta$-cyclodextrin stationary phase, J. Sep. Sci. 30 (2007) 2407-2413; https://doi.org/10.1002/ jssc. 200600529

14. I. R. Miksa, M. R. Cummings and R. H. Poppenga, Multi-residue determination of anti-inflammatory analgesics in sera by liquid chromatography-mass spectrometry, J. Anal. Toxicol. 29 (2005) 95-104; https://doi.org/10.1093/jat/29.2.95

15. X. Chen, J. Huang, Z. Kong and D. Zhong, Sensitive liquid chromatography-tandem mass spectrometry method for the simultaneous determination of paracetamol and guaifenesin in human plasma, J. Chromatogr. B 817 (2005) 263-269; https://doi.org/10.1016/j.jchromb.2004.12.011

16. K. R. Ing-Lorenzini, J. A. Desmeules, M. Besson, J.-L. Veuthey, P. Dayer and Y. Daali, Two-dimensional liquid chromatography-ion trap mass spectrometry for the simultaneous determination of ketorolac enantiomers and paracetamol in human plasma: Application to a pharmacokinetic study, J. Chromatogr. A 1216 (2009) 3851-3856; https://doi.org/10.1016/j.chroma.2009.02.071 
17. A. Gałuszka, Z. Migaszewski and J. Namieśnik, The 12 principles of green analytical chemistry and the SIGNIFICANCE mnemonic of green analytical practices, Trends Anal. Chem. 50 (2013) 78-84; https://doi.org/10.1016/j.trac.2013.04.010

18. M. Tobiszewski, A. Mechlińska and J. Namieśnik, Green analytical chemistry-theory and practice, Chem. Soc. Rev. 39 (2010) 2869-2878; https://doi.org/10.1039/B926439F

19. L. H. Keith, L. U. Gron and J. L. Young, Green analytical methodologies, Chem. Rev. 107 (2007) 2695-2708; https://doi.org/10.1021/cr068359e

20. A. Gałuszka, Z. M. Migaszewski, P. Konieczka and J. Namieśnik, Analytical eco-scale for assessing the greenness of analytical procedures, Trends Anal. Chem. 37 (2012) 61-72; https://doi. org/10.1016/j.trac.2012.03.013

21. G. Corcoran, J. Mitchell, Y. Vaishnav and E. Horning, Evidence that acetaminophen and N-hydroxyacetaminophen form a common arylating intermediate, $N$-acetyl- $p$-benzoquinoneimine, Mol. Pharmacol. 18 (1980) 536-542.

22. D. Nematollahi, Y. Nasseri, A. Amani and F. Fatemi, Kinetic and mechanistic study of drug-drug interaction between acetaminophen and $\beta$-lactam antibiotics, Progr. Reac. Kin. Mech. 38 (2013) 213-219; https://doi.org/10.3184\%2F146867813X13642226149240

23. International Conference on Harmonization $(\mathrm{ICH})$ of Technical Requirements for the Registration of Pharmaceuticals for Human Use, Validation of analytical procedures: text and methodology, ICH, Geneva, November 2005. 